\title{
Stabilisation of the [6]-prismane structure by silicon substitution ${ }^{\dagger}$
}

\author{
ASIF EQUBAL $^{\mathrm{a}}$, SHWETHA SRINIVASAN ${ }^{\mathrm{a}}$ and NARAYANASAMI SATHYAMURTHY ${ }^{\mathrm{a}, \mathrm{b}, *}$ \\ ${ }^{a}$ Department of Chemical Sciences, Indian Institute of Science Education and Research (IISER) Mohali, Sector \\ 81, SAS Nagar, Manauli, 140 306, India \\ ${ }^{\mathrm{b}}$ Department of Chemistry, Indian Institute of Technology Kanpur, Kanpur, 208 016, India \\ E-mail: nsath@iisermohali.ac.in
}

MS received 9 January 2017; revised 6 March 2017; accepted 17 March 2017

\begin{abstract}
Using the second-order Møller-Plesset perturbation (MP2) theoretic method and the cc-pVDZ basis set, it is shown that with an increase in the number of carbon atoms substituted by silicon, the [6]-prismane structure becomes increasingly more stable, relative to the two isolated benzene (like) structures. A similar trend is observed for germanium substituted prismanes as well. Extending this investigation, the stability of benzene-capped fullerene ( $\mathrm{C}_{60}$ fused with benzene) is also investigated.
\end{abstract}

Keywords. [6]-Prismane; silabenzene; germanobenzene; benzene-capped fullerene.

\section{Introduction}

Benzene is known to be highly stable. The interaction of two benzene molecules has been investigated over the years, and the parallel displaced and T-shaped geometries have been shown to be comparable in stability from a theoretical point of view. ${ }^{1-4}$ However, experimental evidence obtained thus far indicates the benzene dimer to be T-shaped. ${ }^{5-7}$

While benzene is known to interact strongly with cations and to form sandwich complexes with them, ${ }^{8-10}$ the fused dimer in which two benzene moieties form covalent bonds in a face-to-face configuration is energetically unstable. ${ }^{11}$

The present paper reports on the effect of silicon substitution on the stability of fused benzene dimer configuration, known as [6]-prismane.

Prismanes are a class of hydrocarbons consisting of a series of fused cyclobutane rings with a generic chemical formula $\left(\mathrm{C}_{2} \mathrm{H}_{2}\right)_{n}$, where $n$ is the number of cyclobutane rings. ${ }^{12,13}$ The simplest member, triprismane or [3]-prismane, $\left(\mathrm{C}_{6} \mathrm{H}_{6}\right)$ is considered an isomer of benzene. ${ }^{14}$ Many ab initio quantum chemical investigations have been carried out to examine the structural and thermodynamical properties of [n]-prismane along with the effect of substitution on its mechanical properties. ${ }^{15-21}$ While the synthesis of lower prismanes $(n<6)$ was

\footnotetext{
*For correspondence

$\dagger$ Dedicated to the memory of the late Professor Charusita Chakravarty.
}

readily achieved, ${ }^{22-25}$ synthesis of [6]-prismane remained a challenge until Mehta and Padma ${ }^{26,27}$ came up with a novel idea to synthesize it using Diels-Alder addition and photocatalysis. [6]-Prismane has the structure of a regular hexagonal prism wherein two parallel 6membered rings are co-joined face-to-face resulting in the formation of six cyclobutane rings (Figure 1). Alonso et al. ${ }^{28}$ have studied the thermally forbidden [6+6] cycloaddition of two aromatic benzene rings and examined the aromaticity profile along the reaction coordinate. In general, any [n]-prismane can be considered as a dimer of an n-membered conjugated ring.

The present work focuses primarily on the feasibility of [6]-prismane formation. Many synthesized as well as theoretically predicted benzene dimers have been reported in the literature [see above]. Rogachev et al., ${ }^{11}$ have investigated twelve different forms of benzene dimers, of which four were reported theoretically for the first time. Their calculations at the MP2/cc-pVTZ level of theory for the new benzene dimers featuring one or more cyclohexadiene rings emphasized a destabilisation energy of 50-99 kcal/mol, relative to the two isolated benzene molecules. [6]Prismane differs from the other benzene dimers due to the absence of cyclohexadiene rings. A $b$ initio calculations suggest the $D_{6 \mathrm{~h}}$ symmetry to be the lowest energy arrangement with an interaction energy of $+115 \mathrm{kcal} / \mathrm{mol}$ relative to the two isolated benzene molecules, indicating that [6]-prismane is an unstable benzene dimer. 
Although carbon and silicon belong to the same group in the periodic table, there is a distinct difference in their bonding abilities. Innumerable unsaturated carbon compounds exist, but unsaturated silicon compounds are rare as silicon prefers an $\mathrm{sp}^{3}$ bonding environment over $\mathrm{sp}^{2}{ }^{29-32}$ For the same reason, compounds containing $\mathrm{Si}=\mathrm{Si}$ bonds transform readily into their saturated form. Mohan and Dutta ${ }^{33}$ studied theoretically the structural properties of a series of silicon substituted benzene $\left(\mathrm{C}_{n} \mathrm{Si}_{(6-n)} \mathrm{H}_{6}, 0 \leq n \leq 6\right)$ molecules and the stability of their complexes with elemental chromium. These silicon substituted benzene moieties have $\mathrm{Si}=\mathrm{Si}$ bonds and they exhibit a pseudoJahn-Teller (PJT) distortion owing to the interaction between the close lying highest occupied molecular orbital (HOMO) and the lowest unoccupied molecular orbital (LUMO). ${ }^{34,35}$ Due to PJT distortion, three Si atoms in conjugation undergo puckering or buckling to attain the favourable $\mathrm{sp}^{3}$ hybridization. Buckling leads to stabilization of the $\sigma$ backbone and a simultaneous destabilization of the $\pi$ backbone. Jose and Dutta have elucidated puckering in silicenes in great detail elsewhere. ${ }^{36,37}$

By a detailed analysis of the vibronic interactions in two or more benzene molecules stacked on top of each other, Boltrushko et al., ${ }^{38}$ have shown that Jahn-Teller effect could account for a lowering of the barrier for di-benzene formation (although such a dimer is energetically less stable than the separated benzene molecules). However, when three or more benzene moieties were stacked on top of each other, the PJT effect led to buckling within each ring.

There is substantial experimental evidence ${ }^{39}$ for the formation of silicon/germanium analogs of tetrahedrane, [3]-prismane and [4]-prismane (cubane), but none so far for the $\mathrm{Si} / \mathrm{Ge}$ analogs of [6]-prismane. Hopefully, our results would spur new experimental efforts to make $\mathrm{Si} / \mathrm{Ge}$ analogs of [6]-prismane.

Our theoretical investigations show that [6]-prismane made up of silicon substituted benzene moieties are stable with respect to their silicene monomers (see below).
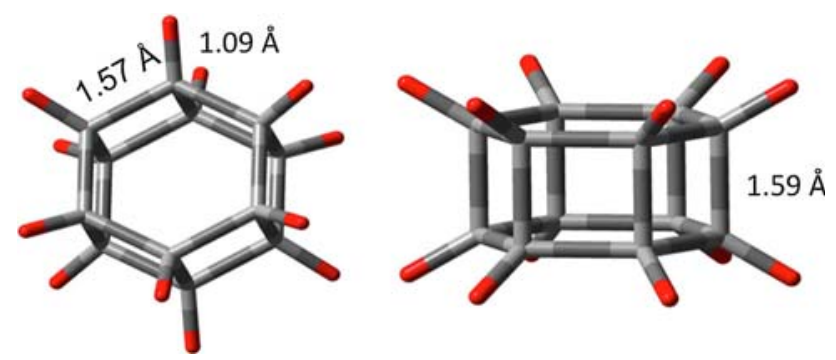

Figure 1. Structure of [6]-prismane, top and side view.
To obtain a detailed understanding of the enhanced stability of the dimer of hexasilabenzene $\left(\mathrm{Si}_{6} \mathrm{H}_{6}\right)_{2}$ over [6]-prismane formed by two benzene units, we have investigated systematically the stability of sequentially substituted silabenzene dimers.

\section{Computational details}

All electronic structure calculations were carried out using the Gaussian 09 suite of programs. ${ }^{40}$ Although initial geometry optimization for the different prismanes and capped fullerene was done using the Hartree-Fock (HF) method and the 6-311G basis set, additional calculations were at the second-order Møller-Plesset perturbation (MP2) theoretic level using the Dunning's correlation consistent double zeta (cc-pVDZ) basis set. Frequency calculations were carried out to ensure that all the optimized geometries obtained corresponded to true minima. The stabilization or the interaction energy $(\Delta E)$ for the dimer was computed as,

$$
\Delta E=E_{\text {dimer }}-2 E_{\text {monomer }}
$$

for both $\mathrm{Si}$ - and Ge- substituted prismanes. For the benzene capped fullerene,

$$
\Delta E=E_{\text {capped-fullerene }}-E_{\text {benzene }}-E_{\text {fullerene }} .
$$

Negative values of $\Delta E$ indicate stabilisation of the dimer or the capped fullerene.

\section{Results and Discussion}

The face-to-face dimer ([6]-prismane) formed by the covalent interaction between two benzene rings is unstable relative to the two benzene monomers by an energy $(\Delta E)$ of $125 \mathrm{kcal} / \mathrm{mol}$ at the MP2/cc-pVDZ level of theory. Such an instability can be accounted for by the loss of aromaticity (each benzene moiety has a resonance energy of $36 \mathrm{kcal} / \mathrm{mol}$ ) and the formation of six highly strained cyclobutane rings. These two factors severely negate the stability gained by the formation of $\sigma$ bonds between the monomers even though the newly formed $\sigma$ bonds are significantly stronger than the previously present $\pi$ bonds. In the case of singly substituted silabenzene, dimerization is energetically unfavourable by $42.9 \mathrm{kcal} / \mathrm{mol}$. The Si-Si bond in the dimer provides the $\mathrm{Si}$ atoms with their favourable $\mathrm{sp}^{3}$ bonding environment. Additionally, the number of cyclobutane rings formed on dimerization is reduced to 4 due to the presence of one $\mathrm{Si}$ atom in place of $\mathrm{C}$ when compared to 6 in benzene dimer. The longer Si-Si bond length lowers the angular strain in the remaining 2 rings. 
For multi-Si-substituted benzene, the stability of the dimer depends on the position of $\mathrm{Si}$ atoms in the ring. In the case of doubly substituted benzene ring, the dimer formed by 1,2-disilabenzene is slightly unstable $(\Delta E=+0.5 \mathrm{kcal} / \mathrm{mol})$ as it leads to the formation of three cyclobutane rings, whereas those formed by 1,3-disilabenzene $(\Delta E=-10.6 \mathrm{kcal} / \mathrm{mol})$ and 1,4 disilabenzene $(\Delta E=-21.8 \mathrm{kcal} / \mathrm{mol})$ are stable as they lead to the formation of only two cyclobutane rings. Among these two dimers of doubly substituted benzene, 1,4-disilabenzene is more stable as the two cyclobutane rings are separated from each other. However, in 1,3-disilabenzene, the cyclobutane rings are juxtaposed to each other. For the triply substituted benzene, three $\mathrm{Si}-\mathrm{Si} \sigma$ bonds are formed and hence the stability of the dimer is more compared to the dimer of doubly substituted benzene. Among different isomers of tri-substituted benzene dimers, 1,2,3-trisilabenzene dimer is the least stable $(\Delta E=$ $-38.8 \mathrm{kcal} / \mathrm{mol}$ ) as it has two cyclobutane rings and 1,3,5-trisilabenzene dimer is more stable $(\Delta E=$ $-48.5 \mathrm{kcal} / \mathrm{mol}$ ) as no cyclobutane ring is formed. However, 1,2,4-trisilabenzene dimer is the most stable $(\Delta E=-54.4 \mathrm{kcal} / \mathrm{mol})$. The stability of the dimer is further enhanced in the case of the tetrasubstituted benzene dimer. 1,2,4,5-Tetrasilabenzene dimer is the most stable $(\Delta E=-88.4 \mathrm{kcal} / \mathrm{mol})$ as it has no cyclobutane ring and there are four $\mathrm{Si}-\mathrm{Si} \sigma$ bonds. 1,2,3,4-Tetrasilabenzene dimer is the least stable $(\Delta E=$ $-79.3 \mathrm{kcal} / \mathrm{mol}$ ) as it has one cyclobutane ring. 1,2,3,5Tetrasilabenzene dimer has an intermediate stability $(\Delta E=-84 \mathrm{kcal} / \mathrm{mol})$.

Pentasubtituted silabenzene forms a stable dimer with a stabilization energy of $-112.6 \mathrm{kcal} / \mathrm{mol}$. Hexasilabenzene forms the most stable dimer/prismane, with $\Delta E=-134.8 \mathrm{kcal} / \mathrm{mol}$. The molecule belongs to the $D_{6 \mathrm{~h}}$ point group, with six covalent $\mathrm{Si}-\mathrm{Si} \sigma$ bonds between the rings. Figure 2 shows the optimized geometry of different dimers of Si-substituted benzene, while Figure 3 reveals the relative stability of the dimers formed as a function of the number of carbon atoms substituted. The Si-Si bond length in the optimized geometry of the dimers of Si-substituted benzene varies from $2.28 \AA$ to $2.45 \AA$, whereas the C-C bond length in the substituted benzene ring varies from $1.5 \AA$ to 1.65 $\AA$. Natural bond orbital analysis revealed a higher $p$ character in the Si-Si bond formed between monomer layers compared to the planar Si-Si bond. The C-Si bonds are polarized with the $\mathrm{C}$ atom having more than $70 \%$ share of the electrons. Likewise, the $\mathrm{Si}-\mathrm{H}$ bond is also slightly polar with the $\mathrm{H}$ atom being more electronegative and having a share of about $60 \%$ of the bond electrons. A summary of the stabilisation energy values for $\mathrm{Si}$-substituted benzene dimers is given in Table 1.

Since Ge belongs to the same group as $\mathrm{Si}$ and $\mathrm{C}$ in the periodic table, we were curious to know the stability of Ge-substituted benzene and its dimer. We repeated the calculations for Ge-substituted benzene. It was found that planar $\mathrm{Ge}_{6} \mathrm{H}_{6}$ with $D_{6 \mathrm{~h}}$ point group symmetry is not a minimum energy structure, but a second order saddle point. $\mathrm{Ge}_{6} \mathrm{H}_{6}$ exists in a puckered form like $\mathrm{Si}_{6} \mathrm{H}_{6}$ and this can be attributed to the PJT effect as explained by Jose and Dutta ${ }^{36}$ in the case of $\mathrm{Si}_{6} \mathrm{H}_{6}$. The HOMO of $\mathrm{Ge}_{6} \mathrm{H}_{6}$ is doubly degenerate and the LUMO is non-degenerate, similar to the case of $\mathrm{Si}_{6} \mathrm{H}_{6}$. But the HOMO-LUMO energy gap in $\mathrm{Ge}_{6} \mathrm{H}_{6}$ is smaller by $6.5 \mathrm{kcal} / \mathrm{mol}$ than that in $\mathrm{Si}_{6} \mathrm{H}_{6}$. This smaller HOMO-LUMO energy gap leads to a larger PJT effect and hence a larger distortion in the structure of $\mathrm{Ge}_{6} \mathrm{H}_{6}$. This is reflected in an enhancement in the puckering angle, from $34.65^{\circ}$ in $\mathrm{Si}_{6} \mathrm{H}_{6}$ to $46.64^{\circ}$ in the case of $\mathrm{Ge}_{6} \mathrm{H}_{6}$. The Ge-Ge bond length is slightly longer than the $\mathrm{Si}-\mathrm{Si}$ bond length in the optimized geometry of the dimers of substituted benzene. The Ge-Ge bond length varies from $2.4 \AA$ to $2.5 \AA$ and the $\mathrm{C}-\mathrm{C}$ bond length falls in the range 1.5-1.6 $\AA$ in the germanium substituted benzene dimer. A natural bond orbital analysis shows similar features for Ge substituted benzene as observed for Si substituted benzene.

Dimerization energy values for Ge-substituted benzene were calculated the way they were calculated for silicon substituted benzene. A trend similar to that observed for $\mathrm{Si}$ was observed for $\mathrm{Ge}$ as well. That is, on increasing the number of Ge atoms in the benzene ring, the stability of the dimer increased. For single Ge substituted benzene, the dimer formation is energetically unfavorable by $35 \mathrm{kcal} / \mathrm{mol}$. For multiGe substituted benzene, the stability of the dimer, like for multi-Si substituted benzene, depends on the position of the Ge atom in the benzene ring. Vibrational frequency calculations show that 1,2-digermanium benzene, 1,2,3-trigermanium benzene, 1,2,4-trigermanium benzene and 1,2,3,4-tetragermanium benzene are not minimum energy configurations, but are saddle points. The calculations, however, show the dimers to be relatively stable, with respect to the monomers. The dimers of 1,3-digermanium benzene and 1,4-digermanium benzene are stable by about $-30 \mathrm{kcal} / \mathrm{mol}$. The dimer formed by 1,3,5-trigermanium benzene is more stable, with a stabilization energy of $-80 \mathrm{kcal} / \mathrm{mol}$. The stabilization energy due to dimerization in tetra-Gesubstituted benzene is $-107 \mathrm{kcal} / \mathrm{mol}$ and in the case of penta-Ge-substituted benzene, it becomes -120 $\mathrm{kcal} / \mathrm{mol}$. Hexa-Ge-benzene dimer is the most stable 


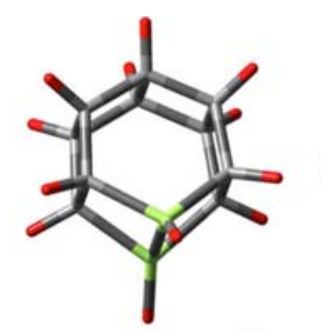

Mono-silabenzene prismane
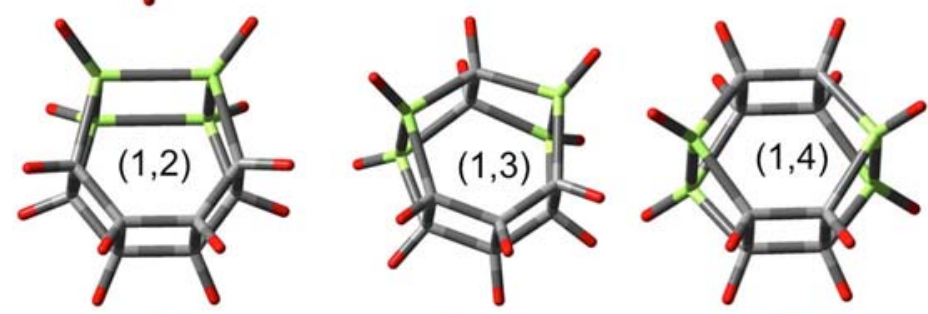

\section{Di-silabenzene} prismane
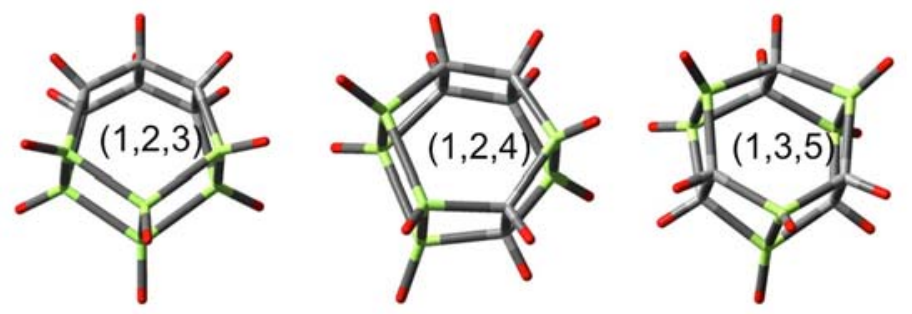

Tri-silabenzene prismane
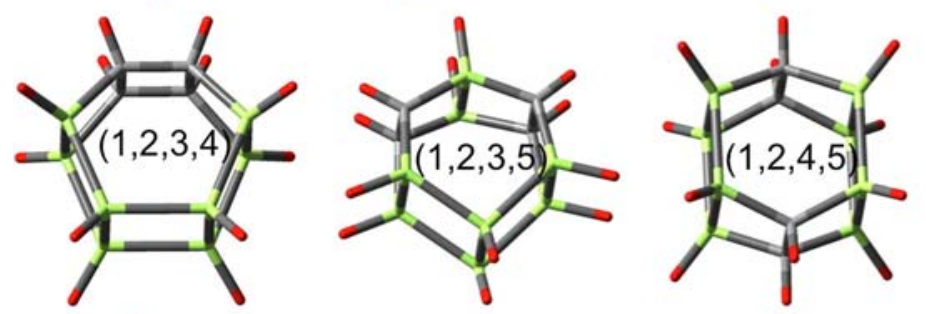

Tetra-silabenzene prismane
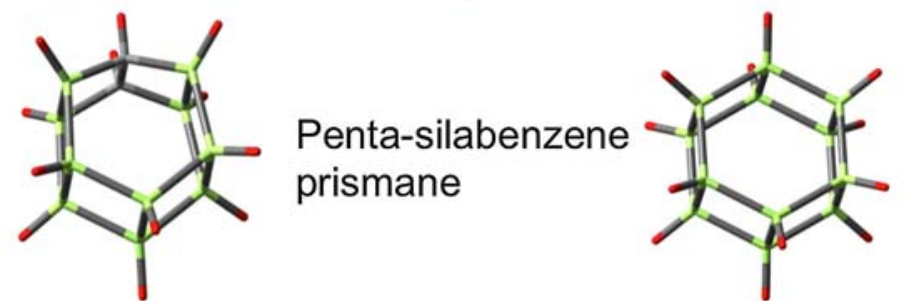

Hexa-silabenzene prismane

Figure 2. Optimized geometry of different silicon-substituted prismane structures obtained at the MP2/cc-pVDZ level of theory. The light green color in the ring indicates silicon atoms.

of all Ge-substituted-benzene dimers, with $\Delta E=$ $-132 \mathrm{kcal} / \mathrm{mol}$. It is evident that the trends observed for Ge substituted benzene are similar to those observed for Si substituted benzene and thus can be explained in a similar manner.

\subsection{Formation of benzene-capped fullerene}

The hexagonal rings of $\mathrm{C}_{60}$ fullerene ${ }^{41}$ have unsaturated carbon atoms, but are less aromatic than the benzene ring due to less planarity. It seemed worthwhile to investigate the covalent interaction between an aromatic benzene and the less aromatic $\mathrm{C}_{60}$ fullerene molecule. We found the face-to-face fusion of the benzene moiety with a sixmembered ring of fullerene, i.e., capped fullerene as the most favourable geometry as illustrated in Figure 4. This structure belongs to the $C_{3 \mathrm{~V}}$ point group. The C$\mathrm{C}$ bond connecting the fullerene cage and the benzene ring is $1.56 \AA$ long, while the $\mathrm{C}$ - $\mathrm{C}$ bond in the cap has a length of $1.55 \AA$. This capped fullerene structure is unstable by $101.3 \mathrm{kcal} / \mathrm{mol}$, with respect to isolated benzene and fullerene moieties, at the HF/cc-pVDZ level of theory. It should be noted that this is lower than the destabilization energy of two benzene molecules forming [6]-prismane, which is $138 \mathrm{kcal} / \mathrm{mol}$ (HF/cc-pVDZ level). 


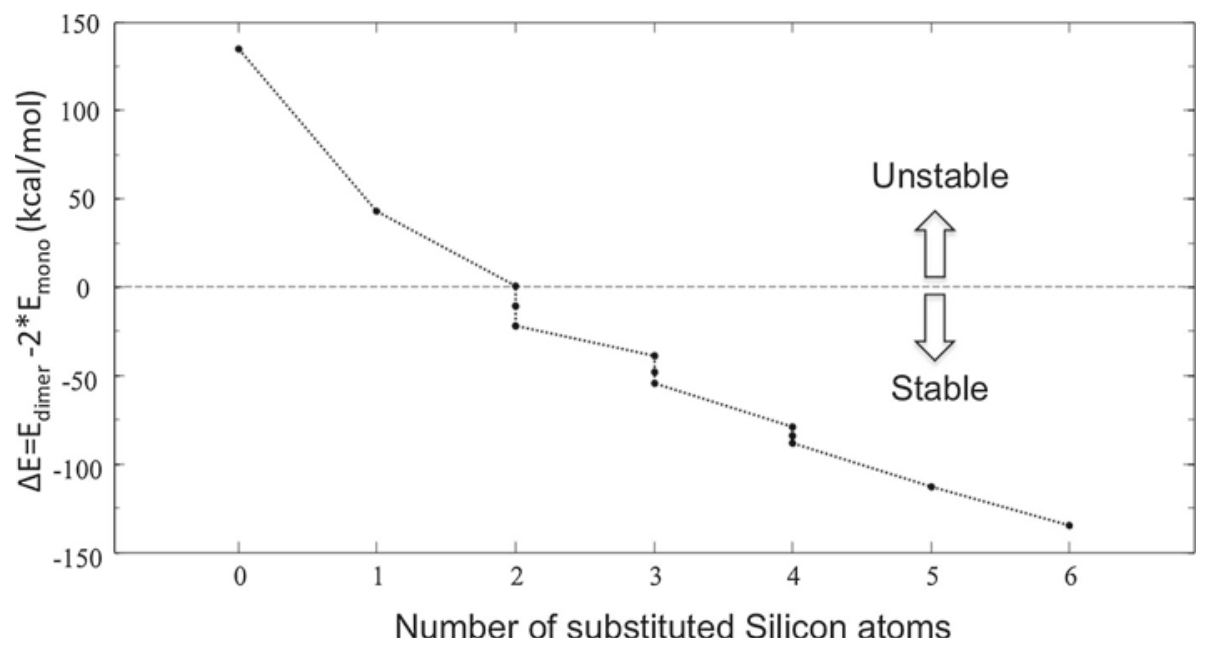

Figure 3. Relative stability of the dimers with respect to the two asymptotically separated monomers of benzene and different Si-substituted benzene moieties at the MP2/cc-pVDZ level of theory.

Table 1. Stabilization energy $(\Delta E)$ values for dimers of different silicon substituted benzene moieties at the MP2/cc-pVDZ level of theory

\begin{tabular}{lcl}
\hline $\begin{array}{l}\text { Monomer: } \\
\mathrm{C}_{\mathrm{n}} \mathrm{Si}_{(6-\mathrm{n})} \mathrm{H}_{6}\end{array}$ & $\begin{array}{c}\Delta E \\
(\mathrm{kcal} / \mathrm{mol})\end{array}$ & $\begin{array}{l}\text { Number of } \\
\text { cyclobutane rings }\end{array}$ \\
\hline $\mathrm{C}_{6} \mathrm{H}_{6}$ & 125.0 & 6 \\
$\mathrm{C}_{5} \mathrm{SiH}_{6}$ & 42.9 & 4 \\
$1,2-\mathrm{C}_{4} \mathrm{Si}_{2} \mathrm{H}_{6}$ & 0.5 & 3 \\
$1,3-\mathrm{C}_{4} \mathrm{Si}_{2} \mathrm{H}_{6}$ & -10.6 & 2 \\
$1,4-\mathrm{C}_{4} \mathrm{Si}_{2} \mathrm{H}_{6}$ & -21.8 & 2 \\
$1,2,3-\mathrm{C}_{3} \mathrm{Si}_{3} \mathrm{H}_{6}$ & -38.8 & 2 \\
$1,2,4-\mathrm{C}_{3} \mathrm{Si}_{3} \mathrm{H}_{6}$ & -54.4 & 1 \\
$1,3,5-\mathrm{C}_{3} \mathrm{Si}_{3} \mathrm{H}_{6}$ & -48.5 & 0 \\
$1,2,3,4-\mathrm{C}_{2} \mathrm{Si}_{4} \mathrm{H}_{6}$ & -79.3 & 1 \\
$1,2,3,5-\mathrm{C}_{2} \mathrm{Si}_{4} \mathrm{H}_{6}$ & -84.0 & 0 \\
$1,2,4,5-\mathrm{C}_{2} \mathrm{Si}_{4} \mathrm{H}_{6}$ & -88.4 & 0 \\
$\mathrm{CSi}_{5} \mathrm{H}_{6}$ & -112.6 & 0 \\
$\mathrm{Si}_{6} \mathrm{H}_{6}$ & -134.8 & 0 \\
\hline
\end{tabular}

Similar calculations were carried out for spherical $\mathrm{Si}_{60}$ capped with hexasilabenzene. It was found that the capped silicon-fullerene was stable with respect to isolated $\mathrm{Si}_{60}$ and $\mathrm{Si}_{6} \mathrm{H}_{6}$ with $\Delta E=-134 \mathrm{kcal} / \mathrm{mol}$. It should be mentioned that icosahedral $\mathrm{Si}_{60}$ is not an energy minimum but a first order saddle point. It would be worth deciphering the properties of capped fullerenes, as it may extend the scope of possible applications of this class of molecules.

\section{Conclusions}

MP2 calculations using the cc-pVDZ basis set showed that the stability of [6]-prismane increased with an

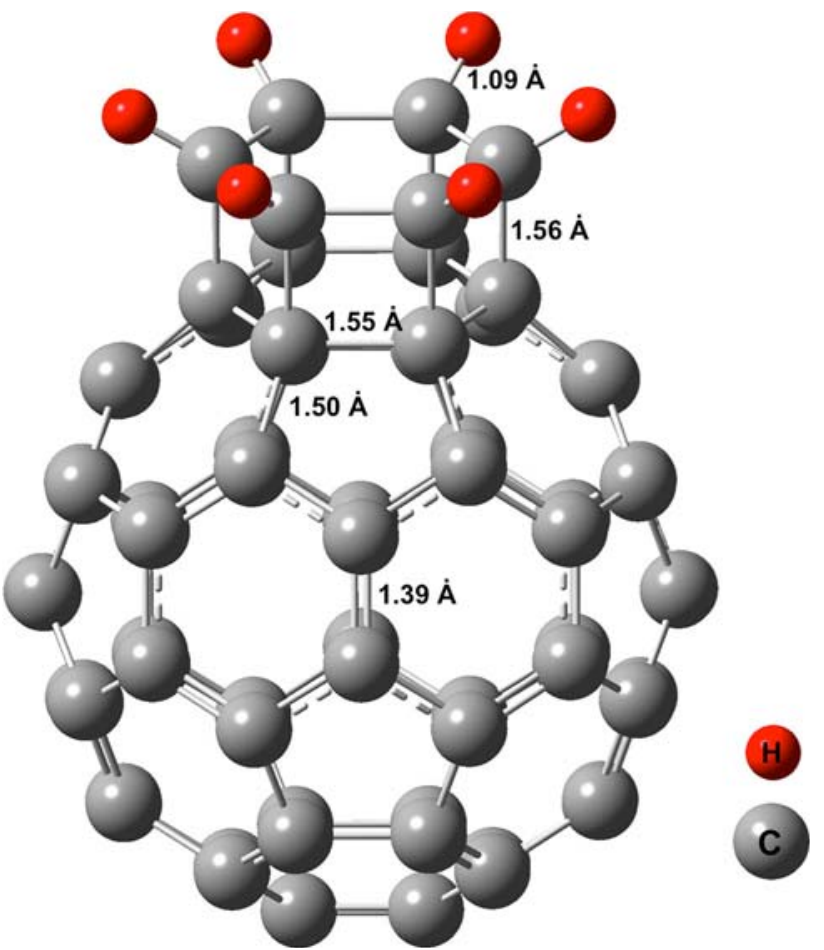

Figure 4. Optimized geometry of benzene-capped fullerene at the HF/cc-pVDZ level of theory.

increase in the number of $\mathrm{Si}$ atoms in each benzene ring, owing to the favourable $\mathrm{sp}^{3}$ bonding environment for $\mathrm{Si}$ and a decrease in the strain energy of the ring due to a reduction in the number of cyclobutane rings formed. A similar trend was observed for Ge substituted [6]-prismane also. It was found that the six membered ring of fullerene and benzene can interact covalently leading to a capped fullerene. The stabilization energy, $\Delta E$, indicates that the interaction between fullerene and 
benzene is more favourable than the dimerization of two benzene molecules.

\section{Acknowledgements}

We are grateful to Professor Murugavel, IIT Bombay for pointing out the literature on the synthesis of $\mathrm{Si}$ and $\mathrm{Ge}$ analogs of some of the Platonic hydrocarbons. NS is an Honorary Professor at the Jawaharlal Nehru Centre for Advanced Scientific Research, Bengaluru. He is grateful to the Department of Science and Technology, New Delhi for a J C Bose National Fellowship.

\section{References}

1. Sinnokrot M O and Sherrill C D 2004 Highly accurate coupled cluster potential energy curves for the benzene dimer: Sandwich, T-shaped and parallel-displaced configurations J. Phys. Chem. A 10810200

2. Park Y C and Lee J S 2006 Accurate ab initio binding energies of the benzene dimer 2006 J. Phys. Chem. A 1105091

3. Milliordos E, Aprà E and Xantheas S S 2014 Benchmark theoretical study of the $\pi-\pi$ binding energy in the benzene dimer J. Phys. Chem. A 1187568

4. Gadre S R, Yeole, S D and Sahu N 2014 Quantum chemical investigations on molecular clusters Chem. Rev. 114 12132

5. Arunan E and Gutowsky H S 1993 The rotational spectrum, structure and dynamics of a benzene dimer $J$. Chem. Phys. 984294

6. Erlekam U, Frankowski M, Meijer G and von Holden G 2006 An experimental value for the $B_{1 u} \mathrm{C}-\mathrm{H}$ stretch mode in benzene J. Chem. Phys. 124171101

7. Chandrasekaran V, Biennier L, Arunan E, Talbi D and Georges R 2011 Direct infrared absorption spectroscopy of benzene dimer J. Phys. Chem. A 11511263

8. Mahadevi A S and Sastry G N 2013 Cation $-\pi$ Interaction: Its Role and Relevance in Chemistry, Biology, and Material Science Chem. Rev. 1132100

9. Kolakkandy S, Pratihar S, Aquino A J A, Wang H and Hase W L 2014 Properties of complexes formed by $\mathrm{Na}^{+}, \mathrm{Mg}^{2+}$, and $\mathrm{Fe}^{2+}$ binding with benzene molecules J. Phys. Chem. A 1189500

10. Dhindhwal V and Sathyamurthy 2016 The effect of hydration on the cation- $\pi$ interaction between benzene and various cations J. Chem. Sci. 1281597

11. Rogachev A Y, Wen X-V and Hoffmann R 2012 Jailbreaking benzene dimers J. Am. Chem. Soc. 1348062

12. Greenberg A and Liebman J F 1978 Strained Organic Molecules: Organic Chemistry: A Series of Monographs Vol. 38 (New York: Academic Press)

13. Lewars E G 2008 In Modeling Marvels: Computational Anticipation of Novel Molecules (Dordrecht: Springer Science)
14. Ladenburg A1869 Bemerkungen zur aromatischen Theorie Ber. Dtsch. Chem. Ges. 2140

15. Disch R L and Schulman J M 1988 Ab initio heats of formation of medium-sized hydrocarbons.7. The [n] prismanes J. Am. Chem. Soc. 1102102

16. Jenkins S J and King D A 2000 Pentaprismane and hypostrophene from first-principles, with plane waves, Chem. Phys. Lett. 317381

17. Dailey W P 1987 The structure and energies of pentaprismane and hexaprismane - An ab initio study Tetrahedron Lett. 285787

18. Shostachenko S A, Maslov M M, Prudkovskii V S and Katin K P 2015 Thermal stability of hexaprismane $\mathrm{C}_{12} \mathrm{H}_{12}$ and octaprismane $\mathrm{C}_{16} \mathrm{H}_{16}$ Phys. Solid State 57 1023

19. Minyaev R M, Minkin V I, Gribanova T N, Starikov A G and Hoffmann R 2003 Poly[ $n]$ prismanes: A family of stable cage structures with half-planar carbon centers $J$. Org. Chem. 688588

20. Pour N, Altus E, Basch H and Hoz S 2009 The origin of the auxetic effect in Prismanes: bowtie structure and the mechanical properties of biprismanes J. Phys. Chem. C 1133467

21. Pour N, Altus E, Basch H and Hoz S 2010 Silicon vs carbon in prismanes: reversal of a mechanical property by fluorine substitution J. Phys. Chem. C 11410386

22. Katz T J and Acton N 1973 Synthesis of prismane J. Am. Chem. Soc. 952738

23. Eaton P E and Cole T W 1964 Cubane J. Am. Chem. Soc. 863157

24. Eaton P E, Or Y S, Branca S J and Shankar B K R 1986 The synthesis of pentaprismane Tetrahedron 421621

25. Eaton P E, Or Y S and Branca S J 1981 Pentaprismane J. Am. Chem. Soc. 1032134

26. Mehta G and Padma S 1987 Secohexaprismane J. Am. Chem. Soc. 1092212

27. Mehta G and Padma S 1991 Synthetic studies towards prismanes: Seco-[6]-prismane Tetrahedron 477783

28. Alonso M, Poater J and Solà M 2007 Aromaticity changes along the reaction coordinate connecting the cyclobutadiene dimer to cubane and the benzene dimer to hexaprismane Struct. Chem. 18773

29. Wang Y and Robinson G H 2009 Unique homonuclear multiple bonding in main group compounds Chem. Commun. 355201

30. Sasamori T, Han J S, Hironaka K, Takagi N, Nagase S and Tokitoh N 2010 Synthesis and structure of stable 1,2-diaryldisilyne Pure Appl. Chem. 82603

31. Takeda K and Shiraishi K 1994 Theoretical possibility of stage corrugation in Si and Ge analogs of graphite Phys. Rev. B $\mathbf{5 0} 14916$

32. Aufray B, Kara A, Vizzini S, Oughaddou H, Léandri C, Ealet B and Le Lay G 2010 Graphene-like silicon nanoribbons on $\operatorname{Ag}(110)$ : A possible formation of silicene Appl. Phys. Lett. 96183102

33. Mohan V and Datta A 2010 Structures and electronic properties of Si-substituted benzenes and their transition metal complexes J. Phys. Chem. Lett. 1136 
34. Tamao K, Kobayashi M, Matsuo T, Furukawa S and Tsuji H 2012 The first observation of electroluminescence from di(2-naphthyl)disilene, an $\mathrm{Si}=\mathrm{Si}$ double bond-containing $\pi$-conjugated compound Chem. Commun. 481030

35. Hobey W D 1965 Vibronic interaction of nearly degenerate states in substituted benzene anions J. Chem. Phys. 432187

36. Jose D and Datta A 2012 Understanding of the buckling distortions in silicene J. Phys. Chem. C 11624639

37. Jose D and Datta A 2014 Structures and chemical properties of silicene: Unlike grapheme Acc. Chem. Res. 47 593
38. Boltrushko V, Krasnenko V and Hizhnyakov V 2015 Pseudo Jahn-Teller effect in stacked benzene molecules Chem. Phys. 46090.

39. Unno M 2014 Substituted polyhedral silicon and germanium clusters Struct. Bond. 15649

40. Gaussian 09, Revision C.01, Frisch M J et al., Gaussian, Inc., Wallingford CT, 2010

41. Kroto H W, Heath J R, O'Brien S C, Curl R F and Smalley R E 1985 C 60 : Buckminsterfullerene Nature 318162 